Image 2:045

\title{
Subcutaneous Scar Retraction Release after Breast Reduction Using Percutaneous Needle Cordotomy
}
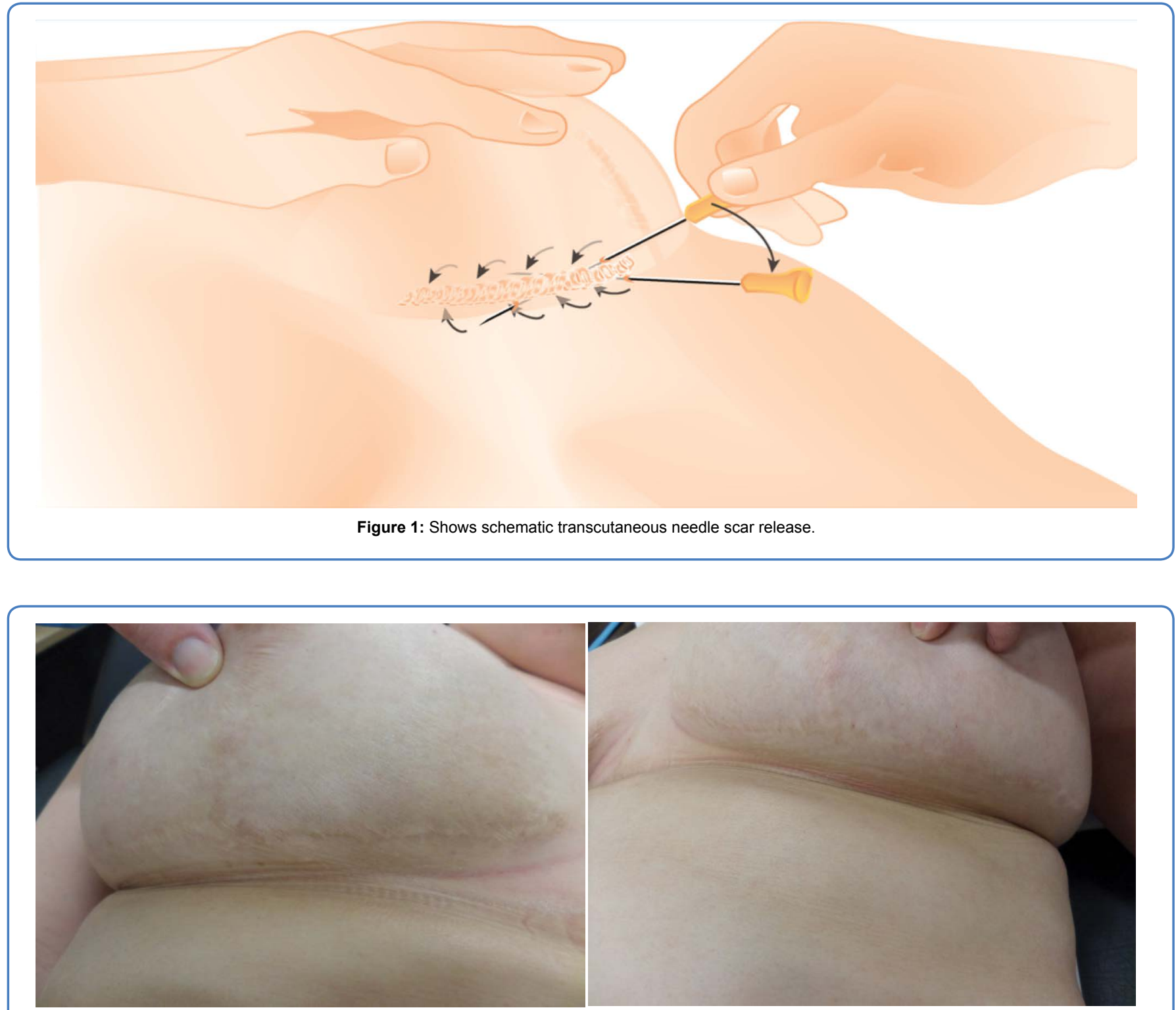

Figure 2: Shows postoperative appearance of the right and left patient's breast. The slightly darker coloured areas were treated with percutaneous scar release.

\section{Information}

\section{$T$ Wagner*, N Slater, M Hameeteman and D Ulrich}

Department of Plastic and Reconstructive Surgery, Radboud University medical center Nijmegen, The Netherlands

*Correspondence: T Wagner, Department of Plastic and Reconstructive Surgery, Radboud University medical center Nijmegen, The Netherlands, E-mail: Till.Wagner@Radboudumc.nl
Citation: Wagner T, Slater N, Hameeteman M, Ulrich D (2016) Subcutaneous Scar Retraction Release after Breast Reduction Using Percutaneous Needle Cordotomy. Clin Med Img Lib 2:045

Published: June 8, 2016

Copyright: () 2016 Wagner T, et al. This is an open-access content distributed under the terms of the Creative Commons Attribution License, which permits unrestricted use, distribution, and reproduction in any medium, provided the original author and source are credited. 
Hypertrophic scarring with scar retraction is a well known problem in breast reduction mammaplasty with occasional unpleasant results for both the patient and surgeon. Even with many different therapeutic options, success can be limited in some cases [1]. We present a case with a simple solution similar to percutaneous needle fasciotomy $[2,3]$.

A 41-year-old woman presented to our outpatient clinic for second opinion of painful bilateral subcutaneous scar retraction tissue. In 2008, she underwent bilateral reduction mammaplasty according to Wise. After consecutive wound dehiscence of the cranial parts of her vertical scar with secondary intention to heal she returned in 2009 for bilateral revision of the horizontal parts of her hypertrophic scars. On first presentation to our hospital five years later, she complained of a thick, painful fibrous subcutaneous cord with a mean diameter of $1 \mathrm{~cm}$ and a length of $6 \mathrm{~cm}$ which had developed spontaneously 6 months prior. She was in good physical condition with a history of mild hypertension, migraine, and smoking (8 cigarettes a day). She stated allergy against amoxicillin. After refusing local steroid injections or other invasive surgical options, we scheduled her at our operative outpatient clinic to test the use and to evaluate transcutaneous needle scar release. Using a 19 gauge needle, we percutaneously disrupted the cord at different levels until pliability was reached (Figure 1). Afterwards, we padded the area with regular dressings. The postoperative course was uneventful. At 2 weeks after surgery, there was a slight intracutaneous hematoma with subcutaneous swelling but no fibrous cord anymore (Figure 2). Three and a half months later, her left medial breast scar was soft whereas her right scar showed less improvement. We saw her back 3 months later for re-evaluation. At that time, she had no further subcutaneous scar retraction tissue on the left, but still in her right lower part of the breast with a length of $4 \mathrm{~cm}$ and width of $0.5 \mathrm{~cm}$. A new subcutaneous scar retraction release using the same technique was performed under local anaesthesia. At 2, 6 and 12 months later, the patient presented for follow-up at our department without any signs of subcutaneous scar retraction and was satisfied with the result.

\section{Conclusion}

In patients with subcutaneous scar retraction problems, needle scar release without lipo filling is a promising option. The procedure creates minimal trauma, is cost-effective and can be performed under local anaesthesia.

\section{Conflict of Interest \\ None.}

\section{Funding}

No funding has been received from any of the authors involved.

\section{Patient Consent}

Patient provided written consent for the use of their images.

\section{References}

1. Felipe Bettini Rabello, Cleyton Dias Souza, Jayme Adriano Farina Júnior (2014) Update on hypertrophic scar treatment. Clinics (Sao Paulo) 69: $565-573$.

2. Bin C, Chenwang D, Xunlei H, Senkai L, Qiang L (2010) Release within scar using the needle-scalpel for treatment of scar contracture of the neck. Plast Reconstr Surg 125: 166e-167e.

3. Foucher G, Medina J, Malizos K (2001) Percutaneous needle fasciotomy in dupuytren disease. Tech Hand Up Extrem Surg 5: $161-164$. 